\title{
IMPLICAÇÕES SOCIOESPACIAIS, ECONÔMICAS E JURÍDICAS EM CONDOMÍNIOS FECHADOS HORIZONTAIS
}

\author{
Adauto Gomes Barbosa* \\ Ademir Araújo da Costa**
}

socio-spatial, economic and legal implications of gated communities)

\begin{abstract}
Resumo
O presente artigo aborda os Condomínios Fechados Horizontais (CFHs) no espaço urbano de João Pessoa, tendo como foco as implicações socioespaciais, econômicas e jurídicas decorrentes da instalação desses produtos imobiliários. Os CFHs representam novas formas espaciais que expressam as transformações do conteúdo social do espaço da capital paraibana. No Litoral Sul pessoense, há um grande estoque de terras não edificadas e não loteadas e de amenidades da natureza que são transformados em atributos de valorização econômica do solo urbano. Neste sentido, o artigo faz uma abordagem dialética para apontar as contradições socioespaciais geradas nesse processo de produção social do espaço. Sob o ponto de vista metodológico, é feito um exame do ordenamento jurídico que rege a expansão da cidade, assim como uma análise da atuação dos agentes capitalistas na produção do espaço urbano, para finalmente apontar a (i)legalidade dos CFHs em João Pessoa. Por fim, o artigo chama a atenção para processos como a redefinição do público e do privado na cidade atual e o crescente espraiamento da morfologia urbana gerado pelos CFHs.
\end{abstract}

Palavras-chaves: João Pessoa, condomínios fechados horizontais, segregação socioespacial, especulação imobiliária.

\begin{abstract}
This article discusses horizontal gated communities (HGC) in the urban area of João Pessoa, focusing on the socio-spatial, economic and legal implications of the implementation of real estate products. The HGC represent new spatial forms that express the transformation of the social content of the space of the capital of Paraiba. In the South Coast of João Pessoa, there is a large stock of land not covered by buildings and not allotted and nature amenities that are transformed into attributes of economic valuation of urban land. In this sense, the article makes a dialectical approach to pinpoint the socio-spatial contradictions generated in the process of the social production of space. From the methodological point of view, it is conducted an examination of the legal system that governs the city's expansion, as well as an analysis of the activities of the capitalist agents on the production of the urban space, to finally point to the (il)legality of HGC in Joao Pessoa. Finally, the article draws attention to processes such as the redefinition of public and private sectors in the city today and the growing sprawl of urban morphology generated by the HGC.
\end{abstract}

Key words: Joao Pessoa, horizontal gated communities, socio-spatial segregation, real state speculation.

\begin{abstract}
Resumen
El presente artículo aborda las Urbanizaciones Cerradas Horizontales (UCHs) en el espacio urbano de João Pessoa, teniendo como foco las implicaciones socio-espaciales, económicas y jurídicas decurrentes de la instalación de esos productos inmobiliarios, las (UCHs) representan nuevas formas espaciales que expresan las transformaciones del contenido social del espacio de la capital paraibana. En el litoral sur pessoense, hay un gran stock de tierras no edificadas y no loteadas y de amenidades de la naturaleza que son transformadas en atributos de valorización económica de suelo urbano. En este sentido, el artículo hace un abordaje dialéctico para señalar las contradicciones socio-espaciales generadas en ese proceso de producción social del espacio. Sobre el punto de vista metodológico, es hecho un examen del ordenamiento jurídico que rige la expansión de la ciudad, así como un análisis de la actuación de los agentes capitalistas en la producción del espacio urbano, para finalmente señalar la (i)legalidad de las (UCHs) en João Pessoa. Finalmente, el articulo llama la atención para procesos como la redefinición de lo público y de lo privado en la ciudad actual y la creciente expansión de la morfología urbana generada por las (UCHs).
\end{abstract}

Palabras-clave: João Pessoa, urbanizacione cerrada horizontale, segregación socio-espacial, especulación inmobiliaria.

(*) Doutorando do Programa de Pós-Graduação em Geografia da Universidade federal de Pernambuco - Av. Prof. Moraes Rego, 1235 - Cidade Universitária, CEP: 50670-901 - Recife (PE), Brasil, Tél: (+ 55 81) 2126.8000 - adauto@recife.ifpe.edu.br

(**) Prof. Dr. da Programa de Pós-Graduação em Geografia da Universidade Federal do Rio Grande do Norte - Lagoa Nova, CEP: 59.072-970 - Natal (RN) - Brasil, Tel/Fax: (+55 84) 32153569 / 32153569 - ademir@ufrnet.br 


\section{INTRODUÇÃO}

O espaço urbano de João Pessoa tem passado por mudanças cada vez mais comuns às médias e grandes cidades brasileiras e uma de suas marcas é a crescente instalação de CFHs que, no âmbito local, representam uma nova configuração socioespacial. Os CFHs são mais que novos produtos imobiliários introduzidos no litoral da cidade. Eles fazem parte de um processo de reestruturação do padrão residencial, caracterizado por certo retorno da casa como espaço de moradia dos segmentos da população que desfrutam de bom poder aquisitivo.

Em João Pessoa, a construção dos CFHs deslanchou no começo dos anos 2000, no Litoral Sul. Recentemente, outras porções da cidade são alvo desses empreendimentos imobiliários. Há ainda a construção em Cabedelo e Lucena, na direção do Litoral Norte paraibano, bem como nos municípios do Litoral Sul do estado, a exemplo de condomínios de praia no município do Conde. É também notória a produção de condomínios de campo em localizações do interior do estado, notadamente nos municípios do Brejo Paraibano. Os condomínios de campo e de praia são geralmente usados como segunda residência e seus lançamentos apresentam forte apelo a uma suposta convivência com a natureza, como o verde, a serra ou o mar.

A despeito dessa expansão em distintos recortes do território paraibano, o presente artigo aborda a inserção desses condomínios no espaço urbano de João Pessoa, levando em consideração tanto as implicações econômicas referentes ao consumo e demanda de solo urbano para a sua implantação, quanto os aspectos jurídicos e as práticas socioespaciais referentes às posturas dos seus moradores. Dessa forma, os CFHs são tratados não apenas como um produto imobiliário, regidos pela lógica estritamente econômica, mas também como uma configuração socioespacial que propicia novas relações socioespaciais na capital paraibana. Trata-se de pesquisa encaminhada durante a realização do mestrado e atualizada, no ano de 2010 , em vista do movimento de expansão desses produtos imobiliários.

A discussão geográfica sobre os CFHs é de natureza espacial e não poderia ser diferente, pois eles apresentam grande demanda por solo urbano. Os promotores imobiliários fazem apologia às amenidades do lugar (quer naturais, quer sociais) e através do marketing procuram relacionar tais empreendimentos a um novo estilo de vida, valores, desejos e necessidades dos seus potenciais consumidores. Estas questões estão ligadas, intrinsecamente, a aspectos de cunho espacial e as reflexões da Geografia sobre os CFHs são muito relevantes para se pensar a reestruturação atual da habitação na cidade de João Pessoa, sobretudo a voltada para os segmentos de médio e alto poder aquisitivo, os quais constituem demanda solvável do ponto de vista do mercado imobiliário.

Com base nisto, o recorte territorial aqui destacado compreende parte do Litoral Sul de João Pessoa, principalmente no setor denominado Altiplano do Cabo Branco, que abarca os bairros de Altiplano Cabo Branco e Portal do Sol. A pesquisa também abrangeu os bairros de Ponta do Seixas, Penha e Costa do Sol. Ainda que em menor grau, estes três últimos bairros fazem parte da dinâmica urbana que ocorre no Litoral Sul da cidade de João Pessoa, conquanto o lançamento dos CFHs ocorra no compartimento geomorfológico do tabuleiro litorâneo, na área do Altiplano do Cabo Branco, com grande estoque de terras disponíveis, além de o novo zoneamento urbano-ambiental impor restrição à verticalização, conforme será discutido adiante.

Tal recorte territorial passou a ser alvo de maior atuação do capital há cerca de uma década e, nos dias atuais, sofre uma forte expansão imobiliária com o lançamento dos CFHs. Há aí uma crescente valorização sob o ponto de vista do mercado imobiliário, graças aos seguintes fatores: localização urbana litorânea; presença de um grande estoque de terras não edificadas e não loteadas, configurando os vazios urbanos; fácil acessibilidade a outras partes da cidade, em especial ao Litoral Norte (possuidor de boa infraestrutura e grande diversidade de serviços); intervenção do Estado por meio de infraestrutura, da instalação de equipamento urbano (Estação Ciência Cabo Branco) e do ordenamento do uso do solo, dentre outros aspectos. 
Ademais, para a compreensão das transformações socioespaciais no referido recorte territorial, outros aspectos espaciais também devem ser considerados: as amenidades naturais; a crescente valorização do solo; a alteração do conteúdo social e econômico e a autossegregação dos moradores dos CFHs. Nesses termos, o Litoral Sul de João Pessoa compõe uma realidade cada vez mais complexa e contraditória. Embora se refiram em particular ao Litoral Sul, as reflexões que aqui são apresentadas ajudam a pensar sobre as transformações que essas configurações socioespaciais têm gerado no âmbito da cidade de João Pessoa como um todo, incluindo, claro, as áreas que mesmo não integrando o município em questão, fazem parte de sua área metropolitana e, assim, estão sob os efeitos da mesma dinâmica urbana.

\section{AS ALTERAÇÕES NO ZONEAMENTO URBANO - AMBIENTAL}

Foi a partir de meados da década de 1970 que a cidade de João Pessoa passou a ser dotada de um marco jurídico para o ordenamento da sua expansão. Com um crescimento bastante acelerado, a administração municipal preocupou-se cada vez mais com o planejamento urbano. Daí se "deflagra o processo de planejamento municipal com a reforma administrativa, a estruturação do cadastro imobiliário urbano e a concepção do PDU (Plano de Desenvolvimento Urbano) que nortearia o crescimento da cidade [...]" (Plano de Desenvolvimento Urbano e Comunitário de João Pessoa PDU - 1983-1986 apud MAIA, 2000, p. 88).

Contudo, o planejamento urbano carecia da existência de um marco jurídico para nortear a gestão urbana. A criação do Código de Urbanismo municipal, em 1975, assumiu esse papel fundamental.

Tal como ocorre com outros inúmeros municípios brasileiros, João Pessoa não dispõe de uma lei específica sobre o parcelamento do solo urbano. Neste caso, a Lei Federal no ${ }^{\circ}$ 6.766/79, que trata do parcelamento do solo urbano, passou a constituir a principal referência legal para a realização do parcelamento do solo na cidade. A definição e a delimitação do zoneamento no âmbito do Código de Urbanismo municipal tinham por objetivo disciplinar as novas direções e o tipo de crescimento de alguns compartimentos da cidade.

Com tal instrumento jurídico municipal, o zoneamento urbano impôs restrições ao uso do solo no Litoral Sul de João Pessoa. O principal propósito era justamente buscar preservar os aspectos estéticos, paisagísticos e ambientais da faixa litorânea, incluindo a Falésia do Cabo Branco.

Desse modo, o zoneamento urbano-ambiental impõe restrições adicionais ao uso do solo para a faixa litorânea, compreendendo a orla marítima, a Falésia do Cabo Branco e o Altiplano do Cabo Branco. Daí porque a preservação dessas áreas é respaldada por instrumentos jurídicos das esferas estadual e municipal. A Constituição do Estado da Paraíba (PARAÍBA, 1989), no Artigo 229, estabelece que em toda faixa de quinhentos metros a partir da maré de sizígia para o continente, a altura máxima permitida das edificações é de doze metros e noventa centímetros, impedindo dessa maneira a construção de espigões na orla.

A mesma restrição está expressa no Artigo 175 da Lei Orgânica do Município de João Pessoa (JOÃO PESSOA, 1990), conforme determinação da constituição estadual. Por sua vez, em relação ao recorte territorial em análise, o Plano Diretor da Cidade de João Pessoa (JOÃO PESSOA, 1994) considera como zonas de restrições adicionais a orla marítima, a Falésia do Cabo Branco e o Altiplano do Cabo Branco.

Diante desse contexto, a apreciação do marco jurídico sobre o uso e ocupação do solo constitui caminho necessário para o estudo do processo de produção socioespacial e da dinâmica urbana no Litoral Sul de João Pessoa. A legislação urbanística em vigor é o principal instrumento que baliza o tipo e o ritmo de expansão que o poder público pleiteia para a cidade como um todo ou para fragmentos de seu espaço urbano, a exemplo do Litoral Sul.

No entanto, é prioritário considerar que a legislação, por si só, não constitui condição suficiente para sanar os problemas urbanos. O planejamento urbano deve estar conectado à realidade concreta da cidade e, inclusive, os gestores públicos precisam enxergar as limitações da legislação 
urbanística. Por mais bem intencionado que se apresente, o planejamento urbano não deve perder de vista o contexto sociocultural local em que está inserido.

No Altiplano do Cabo Branco, as limitações impostas pelo zoneamento asseguraram uma baixa densidade urbana, colocando-se como um aspecto importante do ponto de vista urbano-ambiental. Mas, por outro lado, as mesmas limitações resultaram numa incongruência em relação ao uso do solo do loteamento Cidade Recreio Cabo Branco, pois os lotes localizados próximos da Avenida João Cyrilo da Silva (Avenida Panorâmica) não possuíam o tamanho mínimo permitido legalmente para edificação, de maneira que quem os possuía não podia construir.

Um novo zoneamento urbano-ambiental para o Altiplano do Cabo Branco foi sancionado pela Prefeitura Municipal, por meio do Decreto Municipal $n^{\circ}$. 5.343, de 28 de junho de 2005. De forma semelhante ao zoneamento anterior, os índices urbanísticos impõem fortes restrições ao uso do solo. Para os bairros da Penha e Ponta do Seixas, permanece o zoneamento anterior.

Apesar de pressões das empresas ligadas ao solo urbano, a verticalização continua proibida em grande parte dessa área, salvo na porção a norte do conjunto habitacional Altiplano, na área correspondente aos loteamentos Visão Panorâmica e Jardim Bela Vista. Nos últimos cinco anos, essa área se converteu no metro quadrado mais caro da cidade de João Pessoa, e, justamente lá, estão sendo construídos edifícios residenciais de alto padrão construtivo, cujos preços de apartamentos ultrapassam quinhentos mil reais, conforme atestam anúncios nos jornais locais. Outro efeito do novo zoneamento são os lançamentos de novos CFHs, confirmando a tendência de expansão horizontal desse fragmento da cidade de João Pessoa. A supervalorização imobiliária do Altiplano do Cabo Branco tem transformado sua tradicional imagem de tranquilidade. Aumenta a população residente e, por conseguinte, também o fluxo de veículos na direção desse bairro. Para assegurar a reprodução do capital imobiliário, a iniciativa privada em parceria com a Prefeitura Municipal está abrindo nova pista de acesso ao bairro, para potencializar ainda mais as vendas dos seus produtos imobiliários.

Outra consequência do novo zoneamento é a delimitação da área onde foi inaugurada em julho de 2008 a Estação Ciência Cabo Branco, equipamento urbano construído pela Prefeitura Municipal voltado para atividades de promoção da educação, ciência e cultura, situada nas proximidades do Farol do Cabo Branco, com 680 mil metros quadrados (Figura 1). Tal empreendimento tem impulsionado a valorização do Altiplano do Cabo Branco no mercado imobiliário e está localizado nas proximidades do Farol do Cabo Branco, um dos principais pontos turísticos da cidade, pois a poucos metros também está a Ponta do Seixas, com grande exploração turística por ser o ponto mais oriental da América do Sul.

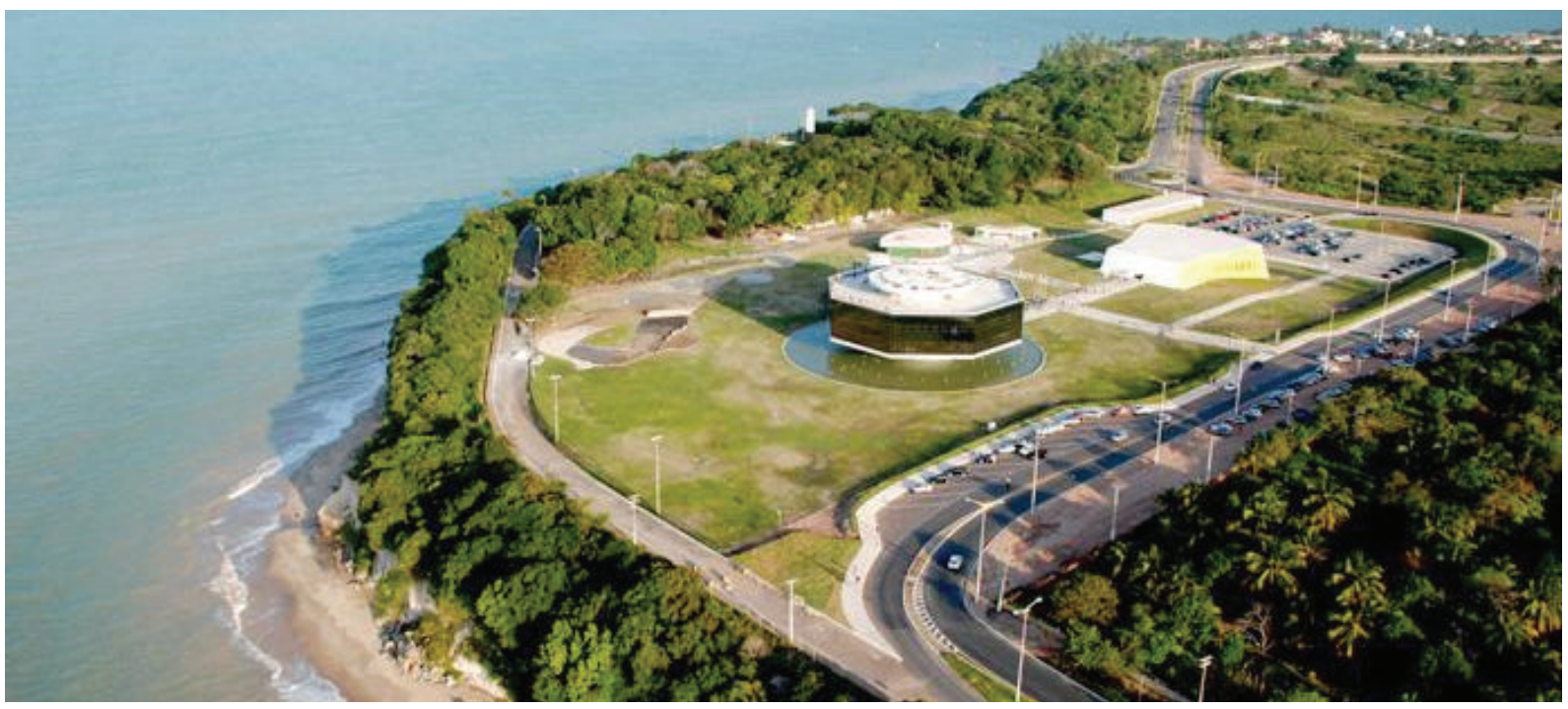

Figura 1 - Estação Ciência, Cultura e Artes Cabo Branco. 
Trata-se de uma obra arquitetônica de grande impacto paisagístico de autoria do renomado arquiteto Oscar Niemayer. O incremento dessa "grife" à área do Altiplano do Cabo Branco não ocorre por acaso, pois faz parte das estratégias do Estado, através da Prefeitura Municipal, de estimular a valorização dessa área de João Pessoa. Merece destaque ainda a criação de um setor de amenização ambiental, o qual compreende as primeiras quadras localizadas ao longo da Avenida João Cyrilo da Silva, em função da proximidade da Falésia do Cabo Branco. A referida avenida, observada na imagem acima, constitui o início da Rodovia Ministro Abelardo Jurema, que, conforme será dito adiante, corresponde à PB 008 e foi concebida para funcionar como corredor do turismo para toda a faixa litorânea sul da Paraíba.

\section{A ATUAÇÃO DOS AGENTES PRODUTORES DO ESPAÇO URBANO}

O Litoral Sul de João Pessoa tem uso do solo predominantemente residencial. O comércio e o setor de serviços são pouco expressivos e algumas atividades rurais, ainda exercidas na área, são apenas residuais. Em função disto, é enfocada a atuação dos agentes construtores da cidade sob o ponto de vista da produção da habitação.

A produção de espaço não envolve apenas os aspectos materiais, pois inclui um conjunto de aspectos imateriais e por vezes subjetivos. Isso significa dizer que a produção do espaço pode ser lida em dois planos de análise.

No sentido amplo, há produção de obras, de idéias, de 'espiritualidade' aparente, em resumo, de tudo o que faz uma sociedade e uma civilização. Em sentido restrito, há produção de bens, de alimentos, de vestuário, de habitação, de coisas. O segundo sentido apoia o primeiro e designa a sua 'base' material (LEFEBVRE, 1972, p. 48, grifos do autor).

Embora possuam diferenças, essas duas concepções de produção não estão dissociadas, ao contrário, complementam-se e são essenciais para a compreensão dos processos que se desenrolam no espaço urbano.

Lefebvre (1991) apreende a cidade e o espaço urbano a partir de conceitos oriundos da linguística: significante e significado, significação e sentido. O autor adverte que a cidade compõe uma grande diversidade de signos, símbolos e códigos, e não apenas um único sistema. Na cidade, há muito mais que produção e consumo de objetos e coisas, há, também, o consumo de signos. "Consome-se tanto signos quanto objetos: signos de felicidade, da satisfação, do poder, da riqueza, da ciência, da técnica etc." (LEFEBVRE, 1991, p. 63-64).

No atual contexto de João Pessoa, a instalação de objetos espaciais, a exemplo de shopping centers, dos CFHs, da estação ciência já mencionada, é permeada por significados, representações e simbolismos que são incorporados pelas pessoas que passam a consumir tais objetos. Para Milton Santos, a realidade tende a ser subsumida em meio ao festival de signos e símbolos, pois "os símbolos baralham, porque tomam o lugar das coisas verdadeiras” (SANTOS, 1997, p. 29).

A produção capitalista da cidade envolve três níveis: a esfera privada, a esfera pública e a sociedade civil. No caso do Litoral Sul de João Pessoa, os agentes mais proeminentes são os proprietários fundiários, os incorporadores, os corretores imobiliários, o Estado e os próprios moradores. Conforme argumenta Corrêa (1995, p. 13), tal separação "é muito mais de natureza analítica do que efetivamente absoluta".

No que tange aos proprietários fundiários, são eles que detêm o monopólio da propriedade privada da terra e seu principal objetivo é extrair renda fundiária urbana, interferindo decisivamente no processo de transformação da terra rural em terra urbana e, por conseguinte, na expansão da cidade. Para eles a terra é mais interessante como valor de troca do que como valor de uso.

A despeito dos oito CFHs na área do Altiplano do Cabo Branco, ainda há a retenção deliberada de algumas glebas, pois os proprietários praticam especulação imobiliária ao reservar terras, de 
forma deliberada, enquanto aguardam maior valorização. Alguns terrenos vagos estão protegidos por muros ou cercas, para reduzir os riscos de ocupações irregulares. Utiliza-se a terminologia "vazios urbanos" para se referir aos terrenos de propriedade particular, que ainda não foram loteados e que, portanto, se constituem em reservas de valor para fins de especulação imobiliária.

Os vazios urbanos são uma necessidade de acumulação do setor imobiliário. Há uma relação dialética entre os terrenos vagos e a cidade. Apesar de configurarem trabalho morto, eles são depositários de valor e se inserem no quadro geral de produção da cidade, cumprindo um papel na realização da reprodução capitalista.

Os vazios urbanos que existem no Litoral Sul são beneficiados por sua localização nas proximidades de áreas loteadas e de vias que dão acesso a distintas partes da cidade de João Pessoa. Ademais, esses terrenos estão próximos dos CFHs, os quais funcionam como vetores de valorização da terra urbana localizada no seu entorno. Por esse motivo, eles não são um dado estático da paisagem. Ao contrário, estão inseridos na dinâmica capitalista da cidade. Conforme afirma Harvey (1980), o solo urbano é uma mercadoria indestrutível e, em si mesmo, não necessita de alguma manutenção para se valorizar. A sua valorização deriva das externalidades, a exemplo da alteração do zoneamento, da instalação de infraestruturas, da melhoria de serviços urbanos, etc. Nesse sentido, os terrenos vagos no espaço interno das cidades estão inseridos no processo de reprodução do capital.

Assim, tal capital necessita da existência de um determinado estoque de terras disponível para assegurar a sua reprodução. Mas, por outro lado, esse estoque também se coloca como um obstáculo à expansão do mercado imobiliário e da construção civil, pois significa terra empatada ou "engessada", ainda que temporariamente.

Em relação aos agentes produtores do espaço urbano, os incorporadores imobiliários assumem um papel decisivo para a realização do empreendimento imobiliário. São os responsáveis pela "gestão do capital-dinheiro na fase de sua transformação em mercadoria, em imóvel" (CORRÊA, 1995, p. 21). Eles potencializam o negócio ao estabelecerem as relações entre os proprietários fundiários e os outros agentes, bem como definem aspectos como tamanho, localização e a qualidade da edificação. Obviamente, essa qualidade depende da clientela-alvo que forma a demanda. Quanto maior sua solvabilidade, melhor tende a ser a qualidade da mercadoria imobiliária.

No que toca aos CFHs, além de exercerem o papel de corretoras, as incorporadoras podem funcionar também como construtoras. Porém, como nos condomínios os lotes a priori são vendidos "nus", sem a edificação, fica a critério do comprador a contratação da empresa construtora ou de outra forma de contrato para a execução da obra. A função de construtora não é tão proeminente nesse tipo de empreendimento quanto a das outras duas.

Atualmente, além dos CFHs Cabo Branco Residence Privê, Residencial Vila Real (ex-Alphavillage), Porta do Sol Residence Privê e do Bougainville Residence Privé, concluídos, outros cinco estão em fase de lançamento no Litoral Sul. São eles: Condomínio Vilas do Farol (com requalifição do edifício do antigo convento católico da ordem dos capuchinhos, que estava em ruínas, onde deverá funcionar um centro comercial), Extremo Oriental Residence Privê, Cidade dos Bosques Cabo Branco, Residencial Bosque das Gameleiras e Residencial Bosque das Orquídeas. Estes três últimos pertencem a uma mesma incorporadora, originária de Natal $(\mathrm{RN})$, a qual tem levado a uma maior consolidação desses produtos imobiliários na área em contexto, pois em parceria com a Prefeitura Municipal promoveu a abertura da Avenida Governador Antônio Mariz, interligando as avenidas João Cyrilo da Silva e Hilton Souto Maior. Com essa nova avenida, abriu-se um acesso à área onde estão sendo instalados os três condomínios, está ocorrendo significativa valorização do solo urbano. Isto só atesta a importância do Altiplano do Cabo Branco para as estratégias do capital imobiliário.

As corretoras responsabilizam-se pela publicidade e comercialização dos imóveis, convertendo o capital-mercadoria em capital-dinheiro, incluindo a margem de lucros. É importante observar que os corretores imobiliários agem na coordenação do mercado imobiliário. São fundamentais para estimular o consumo na medida em que suscitam necessidades e induzem estilos e novas opções de moradias. Em suas operações, fica bastante evidente o tratamento do espaço urbano como um 
campo simbólico (CORRÊA, 1997) ou ainda, como assevera Lefebvre (1991), um espaço permeado por elementos significantes.

Dessa forma, tais agentes criam representações positivas das mercadorias por eles anunciadas. Evocam ainda desejos e necessidades dos clientes-alvo, num processo contínuo que acaba tornando os limites entre ambos muito tênues.

Um exemplo bastante claro dessa estratégia é o lema da campanha publicitária do condomínio Porta do Sol, a qual foi lançada em dezembro de 2004, sintetizada na seguinte frase: "Condomínio Porta do Sol, o lugar perfeito para investir nos seus sonhos". Outro exemplo é a frase colocada no pórtico do CFH Extremo Oriental: "Seja bem-vindo ao paraíso". Se não bastassem estas mensagens, a imagem de pessoas constituindo uma família feliz é parte do subtexto para buscar formar novas demandas. Dessa maneira, é possível captar nos discursos dos sujeitos que passam a viver nos condomínios a absorção desse "novo estilo de vida".

Ao apontar os motivos para morar em condomínio, um dos moradores respondeu: "Aqui nós temos a segurança de um prédio de apartamentos e conforto e liberdade de uma casa". Outros moradores entrevistados também apontaram este argumento. Outro depoimento também é bastante revelador: "A localização [é muito positiva]: longe do Centro e próximo de praias nativas".

Embora as pessoas façam suas escolhas à revelia dos ditames do mercado, sobretudo as que pertencem às classes sociais de alto poder aquisitivo e de maior nível de escolaridade, que é o caso dos condomínios estudados, não há dúvida de que muitos motivos apontados pelos moradores se coadunam perfeitamente com os discursos dos corretores imobiliários. Dessa maneira, a publicidade constitui um imperativo para a formação de novas demandas e assim proporcionar a reprodução do capital.

Os empresários questionados defendem e almejam o incremento do turismo como uma atividade geradora de novos negócios no setor imobiliário. Questionados sobre quais os segmentos desse setor apresentam maiores potencialidades no Litoral Sul, foram praticamente unânimes em apontar equipamentos de grande monta voltados para o turismo, como hoteis, restaurantes, resorts e complexos de lazer. Os empresários também defenderam a liberação da verticalização como mecanismo de expansão do mercado imobiliário desse recorte da cidade. Mencionaram ainda os CFHs e o centro de convenções. Não por acaso, essa localização foi selecionada para a construção do Centro de Convenções de João Pessoa, com capacidade para receber grandes eventos. A obra foi iniciada em 2009 e está em fase de conclusão.

Tal postura chama a atenção para a importância estratégica que o Litoral Sul de João Pessoa apresenta para o segmento imobiliário. É interessante frisar que à proporção que o Litoral Norte se torna cada vez mais ocupado e com preços do solo muito elevados, as empresas passam a ter os bairros sul-litorâneos como foco de suas estratégias.

As transformações socioespaciais no Litoral Sul estão relacionadas com o processo de reestruturação que atinge a totalidade da cidade de João Pessoa e, em particular, com os bairros litorâneos onde reside a maior parte dos estratos sociais de maior poder aquisitivo. Os processos que se desenrolam nesse recorte territorial estão inseridos no espaço urbano de João Pessoa como um todo ou ainda podem ser analisados em outras escalas, como a nacional e a internacional, considerando o contexto atual de globalização da economia, ao qual a dinâmica urbana pessoense não está descolada.

\section{A QUESTÃO DA (I)LEGALIDADE DOS CFHs}

De modo semelhante à situação de muitas cidades brasileiras que se defrontam com a difusão dos CFHs como novos produtos lançados pelo mercado imobiliário, o município de João Pessoa não conta, até o momento, com uma legislação que discipline a instalação desse tipo de empreendimento. O Plano Diretor da Cidade de João Pessoa, que está em vigor desde 1994 e ainda não passou por nenhuma revisão, ainda que isto esteja previsto para ocorrer a cada cinco anos, também não estabelece qualquer ordenamento nesse sentido. 
À ausência de legislação no plano municipal se soma a falta de uma lei específica sobre o assunto no plano federal. As leis federais que se referem às intervenções para fins urbanos são a Lei de Urbanização, já citada, e a Lei $\mathrm{n}^{\circ} 4.591$, de 16 de dezembro de 1964. A primeira dispõe sobre o parcelamento do solo para fins urbanos e a segunda trata de condomínio em edificações e das incorporações imobiliárias. Há ainda a Lei no 9.785, de 29 de janeiro de 1999, que altera alguns aspectos da primeira lei mencionada.

A ausência de suporte jurídico para a instalação de CFH justifica-se pelo fato de a Lei Federal $n^{\circ} 6.766 / 79$ ou a Lei Federal $n^{\circ}$ 9.785/99, que a altera e a complementa, não serem aplicáveis a este tipo de empreendimento. Tais leis só se referem a loteamentos abertos, que não é o caso dos condomínios em contexto. Por sua vez, a Lei Federal n n 4.591/64 só se reporta aos condomínios do tipo blocos de apartamentos, separados por vias internas que não constituem ruas e que, portanto, não envolvem o fechamento de logradouros públicos como praças, ruas e jardins, para o conjunto da coletividade urbana, tal como acontece nos CFHs.

Diante deste fato, é feita a seguinte indagação: até que ponto é legalmente permitido erguer muros que fecham loteamentos, impedindo assim a livre fruição das pessoas em áreas que, embora sejam tratadas como privadas, legalmente pertencem ao espaço público? Este fato chama a atenção para a questionável legalidade da aprovação desses empreendimentos por parte da Prefeitura Municipal. É preciso ter clareza de que tal problemática está permeada pelo par dialético necessidades e interesses individuais versus necessidades e interesses coletivos. Mais do que nunca se torna necessário buscar a síntese dessa contradição.

Um dos artifícios adotados pela Prefeitura Municipal para a aprovação de loteamentos fechados tem sido o instrumento jurídico intitulado concessão ou permissão do direito real de uso. Ou seja,

el poder público municipal concede un permiso de uso especial para los residentes de un loteo específico sobre las áreas que se encuentran bajo su dominio (calles, plazas y otras áreas para equipamientos), con lo cual se possibilita y legaliza el cierre de estas urbanizaciones (MIÑO; SPOSITO, 2003, p. 39).

A concessão ou permissão do direito real de uso é um instrumento jurídico aplicável a terrenos públicos ou particulares, por um tempo determinado, daí que constitui um ato contratual. Sua aplicação volta-se para fins de edificação, urbanização ou outra destinação de interesse social. Alguns municípios brasileiros "resolveram" a questão da legalidade dos CFHs aprovando leis que criam e disciplinam a concessão do direito real de uso.

Porém, este instrumento jurídico, que foi criado pelo artigo $7^{\circ}$ do Decreto Federal $n^{\circ} 271$, de 28 de fevereiro de 1967, praticamente ficou "engessado" a partir da sanção da Lei Federal n 8.666, de 21 de junho de 1993, que trata das licitações. Logicamente, essa lei não foi elaborada para respaldar a instalação de CFHs. Ela está sendo aplicada em alguns municípios brasileiros, ante a ausência de legislação que trate dessas novas urbanizações. O artigo $7^{\circ}, \S 3^{\circ}$ estabelece que "a concessão de direito real de uso, tal como ocorre na concessão de uso, depende de aprovação legal e concorrência prévia, admitindo-se a dispensa desta quando o beneficiário for órgão ou entidade de da administração pública [...]" (BRASIL, 2005).

Um aspecto que merece ser questionado é o seguinte: sob que prisma a concessão do direito real de uso para CFHs preenche o quesito relativo ao atendimento do interesse social? Desse modo, ainda que a Prefeitura Municipal procurasse adotar esse caminho, Miño e Sposito (2003) ressaltam a sua questionável legalidade, pois toda concessão de uso é um ato contratual que deve se pautar no interesse da coletividade, o que não seria o caso dos CFHs.

Não há consenso sobre a validade da aplicabilibidade da Lei 8.666/93 para os casos dos CFHs. Como exemplo disso, André Brawerman (2001, p. 15) afirma que, na adoção desse instrumento jurídico, o interesse social seria resguardado, na medida em que "as pessoas que se organizam em loteamento fechado estão dispostas a custear os serviços públicos e equipamentos urbanos que, a princípio, deveriam ser prestados pela Administração Pública”. 
Embora este aspecto se apresente como favorável para o poder público municipal, entende-se que ele não resolve o principal problema constituído por essas "cidadelas fortificadas". Ao impedir a fruição da coletividade urbana no espaço público, os CFHs tornam alguns fragmentos da cidade impermeáveis ao livre acesso da maior parte dos cidadãos. Este fato apresenta implicações no que concerne às práticas socioespaciais que se desenrolam na cidade.

\section{PRÁTICAS SOCIOESPACIAIS ENSEJADAS PELOS CFHs}

Os CFHs erguidos no Brasil não constituem invenções originais, pois derivam de modelos residenciais similares adotados nos Estados Unidos, a exemplo dos Common Interest Developments (CIDs), as incorporações por interesse comum, e dos subúrbios daquele país. Fazendo uma diferenciação entre os condomínios brasileiros e os produtos imobiliários similares estadunidenses, Caldeira (2000) tece importantes considerações. Os condomínios brasileiros são fechados e o acesso é controlado, enquanto que, naquele país, os gated communities (empreendimentos fechados) são apenas $20 \%$ dos CIDs.

Ao contrário do que ocorre nos Estados Unidos, nossos condomínios não são chamados de comunidades, pois, no Brasil, este termo designa as áreas onde moram os pobres, a exemplo das favelas, e, logicamente, as ditas classes média e alta não querem ser confundidas com pobres. "Na verdade, os moradores brasileiros parecem desprezar bastante essa ideia de comunidade" (CALDEIRA, 2000, p. 262). Outra clara diferença dos CFHs brasileiros em relação aos estadunidenses é que, por aqui, as casas não são construídas com o mesmo padrão arquitetônico. De acordo com a autora em contexto, "o alto valor ligado à 'personalidade' da casa, compartilhado por todas as classes sociais, provavelmente explica por que casas padronizadas não são comuns entre a elite" (CALDEIRA, 2000, p. 262).

A propósito, em entrevistas e questionário, os moradores dos CFHs relacionam a casa a algo que proporciona satisfação, status, e, portanto, ficou evidenciado que não se trata apenas de um objeto para fim de moradia, mas o resultado de um longo investimento ou uma conquista, que foi construído seguindo gostos e certos desejos de seus donos. De acordo com Caldeira (2000), nos CFHs brasileiros, a casa é uma espécie de outdoor que anuncia a condição social de seu proprietário. Desse modo,

A moradia e o status social são obviamente associados e em várias sociedades a residência é uma forma de as pessoas se afirmarem publicamente. Em conseqüência, a construção ou aquisição de uma casa é um dos projetos mais importantes que as pessoas irão realizar. A casa faz declarações tanto públicas quanto pessoais, já que relaciona o público e o doméstico. [...] Através de suas casas, os moradores desenvolvem um discurso mediante o qual falam simultaneamente sobre a sociedade e sobre si mesmos (CALDEIRA, 2000, p. 264).

Se de um lado morar em condomínio representa a busca ou valorização da homogeneidade social entre os moradores desses espaços, o mesmo não se pode dizer da homogeneidade do projeto da construção da casa. É preciso considerar que numa sociedade que tem como uma das marcas históricas o patrimonialismo, há uma necessidade de exibir ostentação e de se diferenciar dos outros. A casa, então, cumpre parte deste papel.

A propósito do patrimonialismo, Sorj (2001) afirma que este traço está presente, ainda que em graus variados, em todas as sociedades que apresentam grandes desníveis sociais. Ademais, "Uma das particularidades do moderno patrimonialismo brasileiro está na sua associação com uma extrema desigualdade social, a impunidade de suas elites e o abandono dos setores mais pobres da população" (SORJ, 2001, p. 13). Apesar das profundas transformações que se processam na sociedade e no território brasileiro, a modernidade que aqui se instala tem por marca a permanência ou a não ruptura com o atraso. Miséria e opulência são traços marcantes das cidades brasileiras. 
Quanto maiores elas são, maiores também tendem a ser tais contradições. Entre variados segmentos da elite econômica, prevalece certo sentimento de normalidade ante essa desigualdade. Enquanto isso, a violência na cidade parece ser apenas uma questão de polícia. Isso para não mencionar outros tantos problemas urbanos.

Nesse contexto, os CFHs traduzem novos valores e práticas socioespaciais. Sua análise deve ir além dos aspectos formais, buscando entender como as práticas por eles ensejadas interferem na produção socioespacial. Um exemplo disto é que a emergência desses produtos imobiliários tem grande repercussão nas práticas segregacionistas.

A segregação tem a ver com separação ou apartação e pode ocorrer tanto como um processo voluntário, a auto-segregação das classes de alto poder aquisitivo dos condomínios exclusivos, por exemplo, ou ainda de forma involuntária, como acontece nas ocupações irregulares habitadas pelas camadas de baixo poder aquisitivo. Tal realidade permite inferir que o espaço social onde se projetam e se processam tais tipologias de segregação não configura algo simplesmente "dado", pois o espaço é parte fundamental da construção social e histórica (LEFEBVRE, 1974).

Pode-se dizer também que a segregação socioespacial tem a ver, em última análise, com as distintas condições de acessibilidade desfrutadas pelos diversos segmentos sociais que compõem a cidade. Tal fato se deve fundamentalmente às clivagens de classe e sua repercussão no plano espacial ocorre seja por intermédio da localização da moradia, seja ainda através do desigual acesso aos bens de consumo coletivos (VIEIRA, 2004). Não é demais ressaltar que os bairros mais servidos de infraestrutura e serviços urbanos sob a responsabilidade do Estado são justamente os habitados pelos estratos mais nobres. A equidade territorial é uma realidade distante nas cidades brasileiras. Também não é por acaso que são justamente os estratos mais pobres que ficam mais expostos aos riscos socioambientais e sofrem mais os efeitos de enchentes, deslizamentos e tantas outras iniquidades. Todo esse quadro de referência alimenta a auto-segregação das elites.

Tomando por base Marcuse (2004), ao discutir sobre as várias nuances em que se define o processo de segregação socioespacial, os CFHs configuram um padrão espacial de enclave excludente. Para o mencionado autor,

um enclave excludente (exclusionary enclave) é uma área de concentração espacial na qual os membros de um determinado grupo populacional, definido por sua posição de superioridade em termos de poder, riqueza ou status em relação a seus vizinhos, aglomeram-se de modo a proteger essa posição (MARCUSE, 2004, p. 25).

Na visão desse autor, a formação de um enclave excludente deriva do processo de amuralhamento, que é o mecanismo de autoproteção adotado de forma voluntária por um grupo populacional com vistas à exclusão dos outros. Nesse sentido, podemos afirmar que a produção da cidade e as práticas socioespaciais excludentes a ela vinculadas também produzem a anticidade. Dessa forma, a auto-segregação tem como padrão espacial os enclaves fortificados ou excludentes. Nestes, os moradores separam-se de muitas pessoas que compõem a coletividade urbana, consideradas indesejadas.

Um exemplo disto é que, ao ser questionado sobre os motivos de morar em CFH, um dos moradores do Cabo Branco Residence Privê mencionou como aspectos positivos: “[...] ausência na $[. .$.$] porta de carros com som alto, carros de propaganda, pedintes, vendedores, carro de lixo e$ crentes vendendo religião: a recepção [no caso, a portaria do condomínio] é um filtro" (morador do Cabo Branco Residence Privê, dezembro de 2004). Estas palavras deixam evidente o processo de auto-segregação que ocorre nesses espaços exclusivos.

O discurso do morador demonstra que a opção de morar em CFH é parte da busca da convivência entre os iguais e simultaneamente também representa a negação do diferente e do desigual. Trata-se, pois, da alusão à homogeneidade social interna como um componente valorativo do condomínio fechado enquanto espaço de moradia. Por outro lado, parte dos moradores reclama da ocorrência de certos atritos e da pouca privacidade, em função da proximidade das casas. 
Diante dos problemas relativos à carência de infraestrutura e serviços urbanos no Portal do Sol, a fala de uma líder comunitária do bairro Portal do Sol relata que a instalação desses condomínios na área não contribui para resolver esses problemas, uma vez que os moradores desses espaços auto-segregados se fecham em si e negam as áreas extramuros. O relato seguinte é bem ilustrativo dessa problemática:

[...] os condomínios fechados não são bons para o bairro. É interessante porque valoriza e tudo. Mas aquela população [dos condomínios] fica isolada. Mais uma vez, é como se ela não fizesse parte do bairro. Então vai chegando gente influente que poderia melhorar o bairro, mas como ela está isolada dentro de um muro, ela não está nem aí para o restante da população que está ali em volta (Depoimento de uma líder comunitária, membro da Associação dos Moradores do Bairro Portal do Sol, 2004).

A partir deste depoimento, vê-se claramente o sentido da auto-segregação vivida pelos moradores dos condomínios estudados. Tomando por base as formulações propostas por Souza (2000), a difusão de espaços exclusivos, a exemplo dos CFHs, resulta num processo marcado pela crescente erosão da cidadania e, desse modo, constitui uma forma de escapismo das elites, principalmente em cidades marcadas por uma acentuada fragmentação do seu tecido sociopolítico e espacial.

De forma bastante recorrente, ao apresentarem os motivos que os levaram a residir nesses espaços, constata-se que comumente o que acontece em outras cidades brasileiras, os moradores pesquisados apontaram o fator segurança. Contudo, Sposito afirma que em muitas cidades médias brasileiras, o fator violência não explica por si só essa necessidade ou desejo crescente de morar em CFH. Segundo a autora em contexto,

[...] o aumento da demanda por imóveis em loteamentos fechados tem sido justificado pelo aumento da violência, fato inconteste nas cidades metropolitanas, mas passível de questionamento, em termos da magnitude desse fenômeno urbano contemporâneo, em cidades de outros portes [...] (SPOSITO, 2004, p. 380).

Desse modo, muito embora não se deva descartar o fator segurança como um motivo plausível para se morar em CFH, até o momento presente, os problemas de segurança pública na cidade de João Pessoa não justificariam tamanho medo. Conforme foi dito no corpo teórico deste artigo, há outros elementos que também explicam a busca por este novo estilo de moradia.

Os elementos imagéticos desses empreendimentos imobiliários emprestam prestígio social aos seus moradores, o que só atesta a concepção lefebvreana de que o espaço deve ser interpretado como um campo de significantes e significados. Não se pode perder de vista de que o espaço é uma instância da sociedade que o produziu e, enquanto tal, ele é a própria expressão dessa sociedade. Isso pode até parecer óbvio, contudo, do ponto de vista teórico é fundamental para pensar os problemas da cidade contemporânea e buscar possíveis soluções para seus problemas.

\section{CONSIDERAÇÕES FINAIS}

A presença de fragmentos do espaço urbano do Litoral Sul e cada vez mais de outros compartimentos da cidade de João Pessoa formados pelos condomínios aqui discutidos deriva numa significativa alteração na composição social e econômica do seu espaço urbano. Conforme foi dito neste artigo, não há dúvidas de que esse padrão de crescimento também contribui para a valorização dos vazios urbanos localizados no entorno desses produtos imobiliários, estimulando sobremaneira as práticas especulativas.

A instalação de CFHs induz a importantes transformações na morfologia urbana. Portanto, de forma semelhante ao que ocorre em outras cidades brasileiras, os condomínios aqui investigados se situam em área periurbana, contribuindo assim para criar uma morfologia urbana descontínua 
e espraiada. Além disso, eles alimentam a tendência de crescente fragmentação territorial e social do espaço urbano e de acentuação das práticas de segregação socioespacial. Essa horizontalização da mancha urbana amplia os deslocamentos intraurbanos, bem como a necessidade de o Estado criar novas vias de acesso e dotá-las de infraestruturas e serviços urbanos ainda muito carentes em vários compartimentos da cidade.

Ademais, o lançamento de novos empreendimentos dessa modalidade poderá levar a um fechamento de grande parte dos logradouros públicos ao livre trânsito das pessoas, infringindo abertamente o direito à cidade. Se não bastasse este problema, os estudos sobre os CFHs apontam profundas alterações nas relações de sociabilidade no interior da cidade. Esses aspectos colocam-se como importantes para se tentar compreender as novas problemáticas e dinâmicas do espaço urbano.

Miño e Sposito (2003) chamam a atenção para a redefinição do público e do privado. Os CFHs apropriam-se de espaços públicos, tornando-os privados, na medida em que criam fragmentos territoriais na cidade nos quais as normas de convivência social são autoimpostas e à revelia do restante da cidade. Mais do que nunca, as contradições entre as necessidades individuais e as necessidades coletivas tendem a aflorar no espaço urbano de João Pessoa.

Por fim, espera-se que as questões aqui discutidas tenham levado o leitor a refletir sobre a necessidade cada vez mais premente de ampliar os fóruns de debate sobre a reforma urbana, difundir a urgência de ampliar os mecanismos de participação popular com vistas a uma gestão urbana democrática e alicerçada na chamada inversão de prioridades, onde os interesses coletivos se superponham aos individuais e o público se sobreponha ao privado. Levar a bom termo a equidade territorial é uma questão de justiça socioespacial. A realidade atual de muitas cidades brasileiras está muito distante desse entendimento. Justamente por isso é preciso, mais do que nunca, lutar pelo direito à cidade.

\section{REFERÊNCIA BIBLIOGRÁFICA}

ALVAREZ, Ricardo. Os "vazios urbanos" e o processo de produção da cidade. 1994. 146 f. Dissertação (Mestrado em Geografia Humana) - Universidade de São Paulo, São Paulo, 1994.

BARBOSA, Adauto Gomes. Produção do espaço e transformações urbanas no Litoral Sul de João Pessoa - PB. 2005. 191 f. Dissertação (Mestrado em Geografia) - Universidade Federal do Rio Grande do Norte, Natal, 2005.

BRASIL. Lei Federal n. 8.666/93. Disponível em: <www.planalto.gov.br>. Acesso em: 30 jul 2005.

BRAWERMAN, André. Condomínio fechado: aspectos legais. Revista da Procuradoria Geral do Estado de São Paulo, São Paulo, n. 55/56, p. 1-18, 2001.

CALDEIRA, Teresa Pires do Rio. Cidade de muros: crime, segregação e cidadania em São Paulo. São Paulo: Editora 34/Edusp, 2000.

CORRÊA, Roberto Lobato. O espaço urbano. 3. ed. São Paulo: Ática,1995.

CORRÊA, Roberto Lobato. Trajetórias geográficas. Rio de Janeiro: Bertrand Brasil, 1997.

HARVEY, David. A justiça social e a cidade. São Paulo: Hucitec, 1980.

JOÃO PESSOA. Lei Orgânica para o Município de João Pessoa. João Pessoa: Câmara Municipal de João Pessoa, 1990.

JOÃO PESSOA. Plano Diretor da Cidade de João Pessoa. João Pessoa: Grafset, 1994.

JOÃO PESSOA. Secretaria de Planejamento. Código de Urbanismo. Disponível em: <www.joaopessoa. pb.gov.br>. Acesso em: 04 maio 2003.

LEFEBVRE, Henri. O pensamento marxista e a cidade. São Paulo: Ulisseia, 1972.

LEFEBVRE, Henri. La production de l'espace. Paris: Éditions Anthropos, 1974.

LEFEBVRE, Henri. O direito à cidade. Tradução: Rubens Eduardo Frias. São Paulo: Moraes, 1991. 
MAIA, Doralice Sátyro. Tempos lentos na cidade: permanências e transformações dos costumes rurais em João Pessoa - PB. 2000. 364 f. Tese (Doutorado em Geografia Humana) - Universidade de São Paulo, São Paulo, 2000.

MARCUSE, Peter. Enclaves, sim; guetos, não: a segregação e o estado. Espaço e debates: segregações urbanas. V. 24, n. 45, p. 24-33, 2004.

MIÑO, Oscar A. Sobarzo; SPOSITO, Maria Encarnação Beltrão. Urbanizaciones cerradas: reflexiones y desafios. Ciudades, n. 59, p. $37-43,2003$.

PARAÍBA. Constituição do Estado da Paraíba. João Pessoa: Grafset, 1989.

SANTOS, Milton. Téenica, espaço, tempo: globalização e meio técnico-científico informacional. 3. ed. São Paulo: Hucitec, 1997.

SCHVASBERG, Benny. Tendências e problemas da urbanização contemporânea no Brasil. In: CASTRIOTA, Leonardo Barci. (Org.) Urbanização brasileira: redescobertas. Belo Horizonte: C/ Arte, p. 43 - 63, 2003. SORJ, Bernardo. A nova sociedade brasileira. 2. ed. Rio de Janeiro: Jorge Zahar, 2001.

SOUZA, Marcelo Lopes de. O desafio metropolitano: um estudo sobre a problemática sócio-espacial nas metrópoles brasileiras. Rio de Janeiro: Bertrand Brasil, 2000.

SPOSITO, Maria E. Beltrão. O chão em pedaços: urbanização, economia e cidades no estado de São Paulo. 2004. Tese (Livre Docência) - Universidade Estadual Paulista, Presidente Prudente, 2004.

Trabalho enviado em janeiro de 2011

Trabalho aceito em abril de 2011 